\title{
14
}

\section{Getting Lecturers to Take Discussion Seriously}

\section{Stephen Brookfield}

University of St. Thomas

\section{Stephen Preskill}

University of New Mexico

In this chapter we examine how faculty resistant to experimenting with discussion methods can be encouraged to take them seriously. We begin by acknowledging and addressing publicly the objections to using discussion most frequently raised by skeptical faculty. We then turn to proposing what we believe are the most common reasons why attempts to use discussion sometimes fail: that teachers bave unrealistic expectations of the method, that students are unprepared, that reward systems in the classroom are askew, and that teachers bave not modeled their own participation in, and commitment to, discussion methods. For each of these reasons we suggest a number of responses and strategies.

$\mathrm{O}$ ne of the most fervently cherished hopes of POD members, indeed of faculty developers everywhere, is that of persuading faculty to drop their instinctive reliance on didactic lecturing and turn instead towards active, participatory learning approaches. Central to the success of this effort is getting uninterested faculty to take the discussion method seriously. In this paper we want to explore ways this effort might be accomplished through three complementary strategies: (1) acknowledging and addressing publicly the objections to using discussion most frequently raised by skeptical faculty; (2) warning faculty about the most common reasons why attempted discussions sometimes fail (thereby helping them set up discussions that might be successful); and (3) suggesting some things faculty can do before discussion begins that increase the likelihood of avoiding student silence and that increase faculty's confidence that their use of the method can be successful. 


\section{ACKNOWLEDGING AND ADDRESSING Common Objections to Discussion}

Faculty developers like the two of us usually have an activist bent that impels them to light a fire under colleagues that they are often too quick to stereotype as recalcitrant Neanderthals clinging to outmoded pedagogies. Consequently, when quite legitimate objections are raised by faculty regarding the extent to which the discussion method is realistic or appropriate in a particular situation, faculty developers (ourselves included) can easily fail to address them. We shake our heads sadly and conclude that the objections raised by colleagues demonstrate nothing so much as their evident reluctance to give up power and authority in their classrooms. However, an important early conversation faculty developers need to have with colleagues is one in which legitimate objections to discussion can be acknowledged and addressed. In our experience, the two objections examined below are those that are most frequently raised.

1) Spending time in discussion will allow me less time to cover necessary content tbrougb lectures. The concern about having insufficient time to cover content is felt by teachers who believe that the material they want students to leam is too important to be left to chance. If they lecture, so their argument goes, at least this ensures that the material is aired in students' presence.

We share this same concern. We acknowledge that there are times when lecturing is an efficient way of sketching out the intellectual topography of an area of knowledge for students. In a lecture you can present contrasting schools of thought, group a confusing variety of opinions into general interpretive categories, model intellectual approaches you want your students to emulate, and nurture enthusiasm for a topic by demonstrating your own passionate interest and animated engagement in learning. As Freire acknowledged, "The questions is not banking lectures or no lectures ... the question is the content and dynamism of the lecture, the approach to the object to be known. Does it critically re-orient students to society? Does it animate their critical thinking or not?" (Shor \& Freire, 1987, p. 40).

We have found that in building an argument as to why discussions should be interspersed with lectures (we would never advocate that the one replace the other), it is best to concentrate on the theme of engaging and animating students' attention. We stress that we want our students to engage seriously with ideas and information we think important enough for us to lecture about. We argue that it is risky to expect lectures on their 
own to do this. We point out that building connections-personal and intellectual-is at the heart of discussion. Ideas that seems disconnected when heard in a lecture come alive when explored in speech. We stress that there is no point in covering content for content's sake-the point is to cover content in a way that ensures that students engage with it. It is because we take content so seriously, and we want students to understand certain key ideas accurately and thoroughly, that we feel discussion is indispensable.

One of the traps that advocates of discussion methods often fall into is that of setting up a false dichotomy between lecturing and discussion. As POD members and other skilled faculty developers know, this pedagogic bifurcation is too simplistic. Lectures are not, in and of themselves, oppressive and authoritarian. And lecturers are not, by definition, demagogues. Similarly, discussions are not, in and of themselves, liberating and spontaneous. And discussion leaders are not, by definition, democratic. We have both been participants in discussion sessions where leaders manipulate the group to reach certain predefined conclusions (and we have no doubt done this ourselves). Through their power to control the flow of talk, to summarize and reframe students' comments, and to respond favorably to some contributions and unfavorably to others, discussion leaders can act in extremely authoritarian ways.

Instead of reducing questions of pedagogic method to a simplistic dichotomy-discussion good, lecture bad-we see these two methods as symbiotic. Again, we quote Paulo Freire's observation that "a liberating teacher will illuminate reality even if he or she lectures" (Shor and Freire, 1987, p. 40). Both of us use lectures, simulations, independent study, video, intensive reading, and any other method that works to engage students in learning. For example, both of us love to lecture, and both of us believe that lecturing is often necessary to introduce difficult ideas and to model critical inquiry. Therefore, we have no difficulty in honoring our colleagues' commitment to, and belief in, lecturing. But we do believe that discussion can serve many important purposes and that teachers sometimes abandon discussion too early simply for lack of some creative ideas for implementation.

2) Discussion is fine for "soft" subjects like tbe bumanities and social sciences where disagreement and divergence is possible, even endemic, to the content. But it bas no place in "bard" subjects like matbematics, statistics, and tbe natural sciences. We agree that discussion should be used only when appropriate. In the teaching of unambiguous factual information (for 
example the population of Baltimore in 1850 , the chemical composition of sodium chloride, or Boyle's law) or the inculcation of specific skills (how to open email software or how to give an injection) there seems to be little scope for using the discussion method. However, things are not always as simple as they seem. The exact figure given for Baltimore's 1850 population is actually a human construct, dependent on the data gathering techniques and modes of classification statisticians decide to use, as well as on the learned behaviors of the data gatherers themselves. The hypothetico-deductive method that lies at the heart of intellectual inquiry in the natural sciences is actually a human system of thought developed at a particular moment and place by a particular person (Francis Bacon) and refined over time by philosophical advances in the logic of the scientific method (for example, Karl Popper's principle of falsifiability). What seem to be standardized, objective, and unambiguous skills of computer usage or nursing care are actually protocols developed by particular groups and individuals. Which program or protocol becomes accepted as professionally dominant, as representing commonsense or the norm, depends on which group has the power to promote their way of interpreting good practice over other contenders.

We would argue there is no knowledge that is unambiguous or reified (that is, that exists in a dimension beyond human intervention). The seemingly immutable laws of physics are always applied within a certain range, and the boundaries of that range shift according to research and according to who has the power to define standards for acceptable scientific inquiry. It is also possible to organize discussion around the analysis and interpretation of data from an experiment, allowing students to generate competing hypotheses and discuss how these might be tested. Or, students could discuss the merits of different approaches that they could take toward investigating a mathematical or natural sciences problem.

However, we would also acknowledge that there are times when discussion is not the best way to help students learn something. When we attend workshops to learn how to use the World Wide Web, we don't want to spend the first hour problematizing computer technology. Rather than consider how access to this technology is stratified by class, gender, and race, and how it reproduces existing economic inequities, we want to know which search engine to use. Instead of questioning whether or not this technology privatizes life and thus prevents new social movements that challenge the status quo from forming, we want to know which button to press to display graphics. Of course, we would argue that the best teachers start with learners' needs (such as which search engine to 
use and which button to press) and then nudge students to question the social organization of the very technology they are using.

We would also point to the example of McMaster University in Hamilton, Ontario, where medical students spend three years working in small groups and where Schools of Nursing and Rehabilitation Science organize their whole curriculum around the exploration of clinical cases, problems, and dilemmas in small groups. Ferrier, Marrin, and Seidman (1988) report that, according to their supervisors, graduates of the program perform better in their first years of practice than graduates from other universities. The first attempt pass rate of McMaster students when taking the exams of the Royal College of Physicians and Surgeons of Canada is higher than the national average. Palmer (1998) visited an unnamed large research university where medical students (under the guidance of a mentor) work in small circles to diagnose and treat real patients. In the words of the Medical School dean, "not only did the test scores not decline, but they actually started going up, and during the time we have been teaching this way, they have continued, slowly, to rise. In this approach to medical education, our students not only become more caring but also seem to be getting smarter, faster" (p. 127).

\section{Acknowledging That Discussions Can Fail and Examining Why This Happens}

We need to recognize that teachers new to discussion methods can easily lose heart at their first experiments with the method. Given the complexity of the process this is hardly surprising. It would be almost miraculous if one's early attempts at teaching through discussion were not accompanied by moments of failure and the accompanying temptation to return to tried and trusted methods such as lecturing. In this section we want to examine the most common reasons why teachers jump to the mistaken conclusion that their experiments with discussion are failing. A conversation on these issues with teachers can help them prepare for discussion with a grounded sense of its possibilities.

\section{Teachers' Unrealistic Expectations}

One reason teachers feel their discussion sessions are not working is because they have hopelessly inflated images of what a "successful" discussion looks like. In these visions of "good" discussion there is little silence in the room. What conversation takes place focuses only on relevant issues with a suitably sophisticated level of discourse. Talk flows 
scintillatingly and seamlessly from topic to topic. Everyone listens attentively and respectfully to everyone else's contributions. People make their comments in a way that is informed, thoughtful, insightful, and unfailingly courteous. Wildean epigrams dart impishly across the room interspersed with haiku of great profundity. The Algonquin roundtable or a Bloomsbury dinner party begin to pale in comparison to our febrile imaginings.

The reality is that discussions like this rarely, if ever, happen. Learning to participate in discussion is a lifelong project and most of us go to our graves feeling we still have a lot to learn. Compounding the problem is the fact that two of the most common models of public discourse we have available to us-political debate and TV or radio talk shows-foster an image of conversation as loud, dichotomous, oppositional, and inflammatory. Students who are introverts, or those who need time for reflective analysis, may find the pace and tone of conversation intimidating. If students have suffered public humiliation in previous discussions, or if teachers mandate participation with no case being built as to why students should take the process seriously, then discussion will not work. If students don't know what the teacher's image of a good discussion looks like, or if teachers haven't first modeled their participation in critical, respectful discussions in front of students, then teachers can't blame students for not acting the way they are supposed to.

As teachers we need to justify to students why we believe so strongly in using discussion. Many students will likely have had experiences in classes where teachers manipulated the discussion's outcome and even humiliated their students. Being clear about what we hope to achieve through discussion helps combat students' understandable cynicism and raises our chances of drawing them into conversation. We can clarify our expectations and purposes in a number of ways. For example, a strong statement as to why discussion will be used so much in class can be inserted into the syllabus. One of us includes in his course syllabus a section titled What You Need to Know About this Course. This section is a kind of truth in advertising statement that makes explicit the non-negotiable elements of the course (see Appendix 1).

You can also involve former students in communicating your expectations and purposes to new students. We like to use panels of former students as contributors to the first or second class. These former students come to class and talk about their previous experiences in the course. They are asked to pass on to new students whatever advice they have as alumni on how to survive and flourish in the class. Frequently they end 
up making the case for discussion that you would have made and elaborating on the benefits that you would have stressed. But their testimony is far more powerful. If former students talk about the value of discussion, their comments have far more credibility in the eyes of new students than anything that you as the teacher could say or do.

A variant on this approach is the "letter to successors" technique. In this exercise, current students are asked to compose a letter that will be sent to new students who are entering the same course the next time it is offered. The letter puts into print the departing students' insights about how to survive the experience. After these letters have been written privately, students form small discussion groups to read each other's letters. Group members look for common themes that are then reported back in a whole class plenary session. Because responses are given by a group reporter, anonymity is preserved, and no one is required to say anything about a particular concern of theirs unless they wish to do so. If one or more of these letters contain passages that urge skeptical students to prepare for discussions and to take them seriously, then we try to obtain permission from the students concerned to let us reproduce these comments in the syllabus for the next version of the course.

\section{Students Are Unprepared}

At the beginning of a course teachers often issue unilateral declarations to the effect that "in this class we're going to use discussion." They do this in the confident belief that students will sigh in appreciative relief that finally they have met a teacher who believes in active learning and democratic process.

In reality many students are suspicious, and quite rightly so, of these kinds of unilateral pedagogic fiats. Sometimes they sense the teacher has a covert agenda for the discussion that the students are supposed to guess. Sometimes students just fear looking stupid in front of their peers because they think they don't know enough about something to be able to discuss it intelligently. Often they have no idea what kinds of contributions the teacher values. When discussion becomes a game in which students try to guess what kinds of comments will earn the teacher's approval, the conversation is stilted and hesitant. What looks on the surface like a participatory, democratic experience only serves to reinforce the existing power dynamic. Preparing students for the moral culture and intellectual arena discussion represents is, therefore, crucial to discussion's success. This is where ground rules can help.

Students learn quickly how to gain the teacher's attention in a dis- 
cussion. Get in quickly and say something, anything, so that your participation is noted and logged. In students' minds participation becomes equated with speaking, and not saying anything becomes an indication of one's mental inertia or idiocy. Students' perceptions in this regard are often pretty accurate. Teachers often have an implicit sense that the "best" kinds of discussions are those in which everyone speaks for roughly the same amount of time, with no awkward silences. For students, the pressure they feel to "participate," to say something intelligent, means they devote a great deal of energy to thinking of a point, silently rehearsing what they will say and how they will say it, and then interjecting when they've got their contribution word perfect. The purpose of this careful rehearsal is to make them look smart. Of course, in a perverse, catch-22 manner, by the time they intervene with their perfectly rehearsed contribution the discussion will probably have moved on so they end up feeling ridiculous anyway.

Students know too that discussion groups can quickly become emotional battlegrounds, arenas in which only the strongest egos survive relatively intact. We've all been in discussion groups where a small minority of participants accounted for the greater part of the conversation. We've all seen one forceful individual's personality shut down any meaningful discourse. We've all seen people disagree with another's point in a way that seems personally abusive. And we've all watched while factors of race, gender, and class played themselves out in our discussion groups, reproducing the unequal patterns of communication found in the wider society.

Without clearly defined ground rules that try to ensure an equal chance for everyone to participate, there is little hedge against the dominant few setting the agenda and claiming the air space. Without ground rules that work to help people understand how disagreement can be respectfully expressed, attempts at critical discussion soon descend into abuse or disengagement. Without ground rules that stress how periods of silence are as integral to conversational rhythms as is the most garrulous speech, students think that good discussion participation involves making as many comments as they can fit into the time available.

\section{Evolving Ground Rules for Discussions}

As we argue above, faculty skeptical of discussion are likely to enter into it in a tentative or half-hearted manner. Not surprisingly, a skepticism concerning the possibility of the method's success usually turns into a self-fulfilling prophecy. Students sense the instructor's uncertainty and 
lack of commitment and, in the absence of a clear signal from the instructor concerning the importance of participation, decide that it's not worth the risk or effort to venture into speech. One way to reduce the chances that a cautious approach by instructors will lead to student silence is for teachers to begin by involving the class in setting ground rules for discourse. Rules of conduct and codes of behavior play a crucial role in determining whether or not students take discussion seriously. Although we emphasize that discussions should be completely open regarding the possible directions the conversation could take, and although we're skeptical about the concept of guided discussion, this doesn't mean we're opposed to structuring the process of democratic conversation. There is no contradiction between guiding the ways in which people talk to each other but refusing the guide what they talk about. Our experience is that when students know that there are fair and democratic ground rules that frame how people speak, there is a much better chance that they will get involved.

We advocate to faculty ready to consider experimenting with discussion that they spend some time at the start of a discussion-based course talking with students about the ground rules for conversation that they would like to see in operation. How would students like to be addressed by their peers? What are students' feelings about good manners, respect, or courtesy in discussion and what do these things look like? Do they want discussions to be nothing but talk, or would they like some periods of silence? How do students want to indicate that they're ready to speak? Should we call on people by a show of hands, deciding on the order of contributions by the order in which people raise their hands? Or, should we allow the same few people to have two or three contributions in short order if this leads to a deeper analysis of a particular theme or idea? Before bringing a new person into a discussion should the leader check whether the comment applies to the current theme or if it instead takes the discussion on a new track? How does the group feel about the leader calling directly on individuals to speak (because these students are known to possess particular knowledge or experience that's relevant to the theme being discussed) even if they have not indicated that they wish to do so? One way faculty can generate ground rules is to work from students' most vivid recollections of their experiences as discussion participants. For a description of such an approach, see Appendix 2.

The role of the teacher in this exercise is not to suggest images of how they think good discussants behave. That's the business of group members. However, when it comes to translating these images into specific 
rules of conduct, students do need some help. If the class agrees that good discussions involve lots of people talking, then teachers should work with them to suggest ways to make this more likely. They could suggest some specific possibilities, such as putting a time limit on individual contributions or regularly calling for a circle of voices in which each person in turn is given the floor.

Another approach to evolving ground rules is to ask participants to focus on the "golden rule"; that is, ask them how they would like to be addressed in a discussion and use their responses to frame a code of conduct for how they will speak to others. Again, the instructor's role is to help students move from general declarations such as "I want people to listen carefully to what I'm saying" to specific behaviors (such as suggesting a weekly, circular-response discussion period in which students take turns listening carefully, paraphrasing, and then responding to each other's contributions).

In their work on cooperative learning, Johnson, Johnson, and Smith (1991) emphasize that we cannot assume that students possess the social and communicative skills necessary for collaboration-these need to be taught. The T-Chart they propose is a technique that can be adapted well to help students develop ground rules for discussion. The characteristic of discussion that students desire is written on the top of a large piece of newsprint. Imagine that students say they want their discussions to be respectful. Under the heading "Respectful," the instructor divides the sheet in two, labeling one side "Sounds Like" and the other side "Looks Like." Students and the instructor then suggest items that would fall under each column so that after a few minutes a list is available of how students think respectful discussions look and sound.

Finally, teachers can use videos of discussion vignettes as a useful way to focus students' attention on how they want their discussions to look. The instructions for such an exercise that teachers might give to students can be found in Appendix 3, along with a list of ground rules our students have generated in the past.

\section{Reward Systems Are Askew}

Asking students to invest time and energy in discussion and then grading them on how well they do on mid-terms and finals is akin to telling faculty that teaching is important and then giving tenure only to those with good publishing records. In both situations people know what the real rules of the game are and what behaviors get rewarded. If students know that their final grade depends on the quality of their written work in term 
papers or examinations, then that is where they're going to put their effort.

If teachers are going to ask students to take discussion activities seriously, they need to underscore their intentions by adjusting the rewards system for the course. There need to be clear statements at the outset of the course-both verbally and in the syllabus - of the ways in which serious discussion participation will be expected, recognized, and affirmed. This is why the establishment of unequivocal criteria for participation is so important. Bland, generalized declarations that students will be graded partly on their "participation" ignores the subtleties and complications of race, class, gender, and personality and serves chiefly to induce panic and suspicion in those who don't feel comfortable in the culture of academe. Unfortunately, the situation described by Bean and Peterson (1998) is typical. In studying core curriculum syllabi at their university they note that " $93 \%$ of courses included class participation as a component of course grades. Our informal discussions with professors, however, suggest that most professors determine participation grades impressionistically, using class participation largely as a fudge factor in computing final course grades" (p. 33).

One problem in assessing discussion is that most evaluative systems work in a positivist way. First, an ideal type or exemplar of how an educational process should look is established. The standard of what counts as a proper demonstration of the process is usually determined by polling experts in the field and then translating theoretical tenets into practical terms. Then, whether or not an activity is judged to be done well or poorly is determined by how closely it reproduces these exemplary characteristics. But a discussion cannot be judged by how closely it approximates a decontextualized ideal. Discussions are like marriages-no two are alike and no one on the outside can ever really understand what's happening inside them. Because discussions are always contextualalways shaped by the cultural backgrounds, social classes, genders, experiences, and personalities of their participants - they can only be evaluated from the inside. Therefore, in regard to the evaluation of discussion we generally advocate that teachers work from students' own testimony regarding the nature of their discussion experience.

However, we do acknowledge that even the most phenomenologically inclined teachers have to survive in a system that often puts them through positivist paces. Few of us have the luxury of rejecting standardized evaluative formats, no matter how misconceived we might judge them to be. So we need to use an evaluative approach that at least gives the appearance of being grounded in clear and unequivocal criteria. One 
approach is to assess how well students have observed the rules of conduct that they have evolved to govern the discussion process. If the class has created guidelines for democratic discussion in which several specific behaviors are proposed, then evaluating students' participation becomes a matter of working with them to assess how often these were exhibited. Students could keep a weekly audit of their participation in class discussions and then present a summary and analysis of their entries in an endof-semester learning portfolio. See Appendix 4 for an example of a discussion audit used in a course in which getting students to think critically was a prime objective.

\section{Teachers Have Not Modeled Effective Participation in Discussion}

One of the mistakes we have both made is to walk into a classroom on the first day of a new course, announce to students that we believe in discussion, and tell them why the experience will be good for them. Then we assign topics to students and put them into small discussion groups. The trouble with this scenario is that it omits a crucial element. We have neglected to model in front of the students an engagement in the very activity-participating in group discussion with peers-we are urging on them. As teachers we have to earn the right to ask students to engage seriously in discussion by first modeling our own serious commitment to it. If we want students to believe us when we say discussion is good for them, we have to show them how it's good for us too. So, in any course in which teachers are intending to use discussion methods it's a good idea for them to invite a group of colleagues into the classroom at an early stage in the course. They can then hold a discussion about some aspect of the course's content in which they try to show the kinds of behaviors they'd like students to exhibit in their own subsequent discussions.

As hooks (1994, p. 21) forcefully writes: "in my classrooms, I do not expect students to take any risks that I would not take, to share in any way that I would not share ... it is often productive if professors take the first risk, linking confessional narratives to academic discussions so as to show how experience can illuminate and enhance our understanding of academic material." If instructors are prepared to take this risky, but essential, step of modeling discussion participation in front of their learners, we give some specific guidance. We ask that they make sure to introduce new perspectives by showing how these have been prompted by, or are intended to illuminate, earlier contributions from others. If possible we tell them to clarify in the midst of the discussion how others' comments are helpful in getting them to recognize, and examine critically, some 
familiar assumptions they hold. We suggest they thank colleagues for suggesting radically new interpretations or perspectives they had not previously considered. But they should also feel free to reject these and show that they don't feel duty bound to change their views because of colleagues' comments. We want to show students that it is quite permissible to be the only one holding a dissenting view in a discussion and that groups should avoid trying to convert the lone holdout to majority opinion. We also stress that teachers don't finish by giving a set of conclusions. Instead, they should finish by listing all the unresolved issues and areas for future inquiry that the discussion has prompted.

This modeling can also be used to show students that silence is a necessary and desirable part of conversation. If one colleague asks another a question that she or he has no ready response for, the person asked should feel comfortable saying, "I'm not sure, I'll need a minute or two to think about that" and then take that time before responding. During this period everyone else waits silently. It's been interesting for us to observe how shocked and uncomfortable students are when they see their teachers just sitting quietly as a group while one of us thinks about what we want to say next.

Finally, we urge that faculty try to avoid talking in a rarefied, overly academic manner. They should use specialized terminology when they feel it's warranted but try to mix in plenty of colloquial speech and familiar metaphors. We tell them to be comfortable starting a sentence, then hesitating in mid-sentence, stumbling to find the right words to express their meaning, starting the sentence again, pausing, re-grouping, and then finishing by letting their words trail off. Better to do this than to strive to make ringing, grammatically impeccable, eloquent, and unequivocal declarations of truth. Our concem is that faculty avoid putting on a beautifully articulated, seamless, exemplary display of dazzlingly erudite, high status, academic discourse. We want students to see that hesitations, pauses, and colloquial language are all a normal and valued part of discussion. If we model discussion participation for students, the last thing we want to do is act as if we're characters in a play by Noel Coward or Tom Stoppard.

Although we're advocating modeling the discussion process with colleagues, we want to admit that we have done this far less than we would like. Partly this is because of time. We often worry that we've sacrificed too much time working on process that should be spent studying content. To add a role play of discussion to a course already full of participatory learning activities can seem like overkill. But mostly our prob- 
lem is that it's difficult to convince colleagues that it's worth their while to spend time modeling the discussion process with us. At the very least we can offer to return the favor by helping out our colleagues in whatever way they think is useful.

\section{Conclusion}

One final thought. In our experience, there is no point in proselytizing discussion or trying to convert skeptics into becoming enthusiastic advocates for discussion. Teachers who resolutely dismiss discussion as timewasting, touchy-feely, experiential mush usually only come to take it seriously when they are so dissatisfied with what they're doing that they'll try something new, or when they are irresistibly intrigued by the sense of joyful engagement they witness in their own colleagues' experiments with the method. But we do think there is a category of college teachers out there who are willing to contemplate introducing discussion activities into their classrooms provided they are reassured that this doesn't mean they have to abandon lecturing entirely and provided a good case is built as to the benefits of the method.

\section{REFERENCES}

Bean, J. C., \& Peterson, D. (1998). Grading classroom participation. In R. S. Anderson \& B. W. Speck (Eds.), Changing the way we grade student performance: Classroom assessment and the new learning paradigm (pp. 33-40). New Directions for Teaching and Learning, No. 74. San Francisco, CA: Jossey-Bass.

Ferrier, B., Marrin, M., \& Seidman, J. (1998). Student autonomy in learning medicine: Some participants' experiences. In D. Boud (Ed.), Developing student autonomy in learming. New York, NY: Nichols Publishing.

hooks, b. (1994). Teaching to transgress: Education as the practice of freedom. New York, NY: Routledge.

Johnson, D. W., Johnson, R. T., \& Smith, K. (1991). Active learming: Cooperation in the college classroom. Edina, MN: Interaction Book Company.

Palmer, P. (1993). To know as we are known. San Francisco, CA: Harper Collins.

Palmer, P. (1998). The courage to teach: Exploring the inner landscape of a teacher's life. San Francisco, CA: Jossey-Bass.

Shor, 1., \& Freire, P. (1987). A pedagogy for liberation: Dialogues on transforming education. South Hadley, MA: Bergin and Garvey. 
Contacts:

Stephen Brookfield

Mail \#MOH 217

University of St. Thomas

$1000 \mathrm{La}$ Salle Avenue

Minneapolis, MN 55403-2009

(651) $962-4982$ or (651) 227-6904

(651) 2276904 (FAX)

sdbrookfield@stthomas.edu

Stephen Preskill

College of Education

University of New Mexico

Albuquerque, NM 87131

(505) 277-7784

(505) 277-5553 (FAX)

preskill@unm.edu

Stephen Brookfield is Distinguished Professor at the University of St. Thomas in St. Paul, Minnesota. He is a three-time winner of the World Award for Literature in Adult Education and holds an honorary doctor of letters degree from the University System of New Hampshire for his contributions to understanding adult learning.

Stephen Preskill is Associate Professor of Education and Director of the Division of Educational Leadership and Organizational Learning in the College of Education, University of New Mexico. Together with Stephen Brookfield he is the co-author of Discussion as a Way of Teaching: Tools and Techniques for Democratic Classrooms (San Francisco, CA: Jossey-Bass, 1999). 


\section{APPENDIX 14.1 \\ What You Need to Know About This Course}

As a student, I very much appreciate the chance to make informed decisions about the courses I take. I want to know who the educator is, what her assumptions are, and what she stands for before I make a commitment to spend my time, money, and energy attending the class. So, let me tell you some things about me, and how I work as an educator, that will allow you to make an informed decision as to whether or not you wish to be involved in this course.

I have framed this course on the following assumptions:

1. That participating in discussion brings with it the following benefits:

- It helps students explore a diversity of perspectives

- It increases students awareness of, and tolerance for, ambiguity or complexity

- It helps students recognize and investigate their assumptions

- It encourages attentive, respectful listening

- It develops new appreciation for continuing differences

- It increases intellectual ability

- It helps students become connected to a topic

- It shows respect for students' voices and experiences

- It helps students learn the processes and habits of democratic discourse

- It affirms students as co-creators of knowledge

- It develops the capacity for the clear communication of ideas and meaning

- It develops habits of collaborative learning

- It increases breadth and makes students more empathetic

- It helps students develop skills of synthesis and integration

- It leads to transformation.

2. That students attending will have experiences that they can reflect on and analyze in discussion.

3. That the course will focus on the analysis of students' experiences and ideas as much as on analysis of academic theories.

4. That the chief, regular class activity will be a small group discussion of experiences and ideas. 
5. That $I$, as teacher, have a dual role as catalyst to your critical conversation and as a model of democratic talk.

So, please take note of the following product warnings!

- If you don't feel comfortable talking with others about yourself and your experiences in small groups, you should probably drop this course a.s.a.p.

- If you don't feel comfortable with small group discussion-you think it's a touchy-feely waste of valuable time-you should probably drop this course a.s.a.p.

- If you are not prepared to analyze critically your own and other people's experiences, you probably should drop this course a.s.a.p. 


\section{APPENDIX 14.2}

\section{Generating Ground Rules for Discussion}

As a first step in setting up this discussion group, I suggest that we spend some time trying to create ground rules for our participation. Ground rules are the rules we follow to ensure that the discussion is a useful, respectful, and worthwhile experience for everyone. To help us decide on some rules I would like each of you to do the following:

1. Think of the best group discussions you've ever been involved in. What things happened that made these conversations so satisfying? Make a few notes on this by yourself.

2. Think of the worst group discussions you've ever been involved in. What things happened that made these conversation so unsatisfactory? Made a few notes on this by yourself.

3. Now form a group with 3 other people. Take turns in talking about what made discussion groups work well for you. Listen for common themes, shared experiences, and features of conversation that a majority of you would like to see present in this course.

4. Take turns in talking about what made discussion group work awful for you. Listen for common themes, shared experiences, and features of group conversation that a majority of you would like to see avoided in this course.

5. For each of the agreed-upon characteristics of good discussion, try to suggest three things a group could do to ensure that these characteristics are present. Be as specific and concrete as you can. For example, if you feel good conversation is developmental, with later themes building on and referring back to earlier ones, then you could propose a rule that every new comment made by a participant is prefaced with an explanation as to how it relates to an earlier comment.

6. For each of the agreed-upon characteristics of bad discussion, try to suggest three things a group could do to ensure that these characteristics are avoided. Be as specific and concrete as you can. For example, if you feel that bad conversation happens when one person's voice dominates, then you could propose a rule whereby once someone has spoken they are not allowed to make a second comment until at least three other people have spoken (unless another group member explicitly invites the participant to say something else).

7. Try to finish this exercise by drafting a charter for discussion that comprises the specific, agreed-upon ground rules. We will make each group's rules public and see if we can develop a charter for discussion to guide us in the coming weeks. 


\section{APPENDIX 14.3 \\ Video VigneTtes OF Discussion}

You're going to see two 5-minute excerpts of different discussions. Please watch for the kinds of comments, contributions, and actions that you think are good and bad discussion behaviors. Note these down by yourself. Don't discuss your reactions with others at this stage. You might find it helpful to watch the video with the following questions in mind.

1. In your view, which participants made the best, most helpful, or most useful contributions to the discussion? Why were these contributions so worthwhile?

2. In your view, which participants made the worst, least helpful, or least useful contributions to the discussion? Why were these contributions so irrelevant or unproductive?

3. What changes would you introduce to improve either of these discussions?

Now, compare your responses with the reactions of others in your group. Look particularly for areas of agreement. Based on these, could you suggest any guidelines that would ensure that helpful discussion behaviors are encouraged?

When we reconvene we will see if your notes can help us decide on the discussion guidelines we want to follow in this course.

The following are some examples of ground rules generated by different groups with whom we have worked.

- Faculty are not to call on students by name to speak, though students may call upon each other.

- Students designate an umpire for each discussion to ensure rules for respectful discourse are followed.

- Students are not to interrupt each other.

- Students are to show their desire to intervene in a conversation by raising their hands and the umpire or facilitator will keep track of the order.

- Students do not have to raise their hands to intervene-just jump in when they're ready.

- To build connections and show appreciation we must strive to preface our comments with a declaration of how it builds on, adds to, contradicts, or departs from an earlier contribution. 
- In deciding who gets to speak next, the chair, umpire, or facilitator always gives preference to those who wish to speak but have not yet spoken.

- Every 15 minutes or so we are to pause for a reflective interlude.

- Every 15 minutes or so we are to run a circle of voices in which all those who have not spoken in the previous period have the floor if they wish to say something. 


\section{APPENDIX 14.4 \\ Discussion Audit Instructions}

Please write down anything that occurs to you about your contributions to, and learning within, the discussions we've had in class this week. If you want, you can record your thoughts in a free-flowing way. For those of you who like more structure, it might be helpful to consider the following questions. Don't feel you have to answer every one, or even any of them-they're just here to help your reflections.

- List the assumptions that you held about the topic of the discussions this week that were uncovered or clarified for you.

- Of all these assumptions, which did you feel were accurate and valid? Try to write down what was said during the discussion that confirmed the accuracy of your assumptions.

- Of all these assumptions, which did you feel were most challenged by the discussion? Try to write down what was said during the discussion that challenged the accuracy of your assumptions.

- What different perspectives on the topics were suggested for you by our discussions?

- What's the most important learning you've taken from this week's discussions?

- What's the most pressing question(s) you're left with about the topic as a result of this week's discussions?

- In what ways did you, and other group members, observe and implement the class rules for discussion?

- In what ways did you, and other group members, contradict the class rules for discussion?

- After your experience this week, which of these class rules should be amended or abandoned? And what new rules would you like to propose?

Midway through the semester, and then again at the end, you will be asked to read what you've written each week about your discussion experiences. You will be expected to prepare a summary in which you identify patterns, similarities, contradictions, discrepancies, and surprises. This summary (not individual weekly entries) will be a part of your learning portfolio for the course.

An option that is less time consuming than the audit is to ask students to keep a short discussion log. A discussion $\log$ is a set of brief responses to three questions. 
1. What do you know as a result of participating in this discussion that you didn't know this time last week?

2. What can you do as a result of participating in this discussion that you couldn't do this time last week?

3. What could you teach someone as a result of participating in this discussion that you couldn't teach them this time last week?

The information in this log can then be used in two possible ways. Students can submit their responses to you once a week and you can start the next class by summarizing their responses. Used this way it is crucial that students know their anonymity is assured. No names are allowed on the logs that students submit. Or, taking a more longitudinal approach, students can use these logs as primary data for a report on their discussion learning that they will include in their portfolios. 